\title{
Good Laboratory Practice (GLP) in The European Union
}

\author{
Viviane Annisa $^{*}$ \\ ${ }^{*}$ Pasca Sarjana Farmasi, Fakultas Farmasi, Universitas Gadjah Mada, Yogyakarta, Indonesia. \\ *E-mail:vivianeannisa@ugm.ac.co.id
}

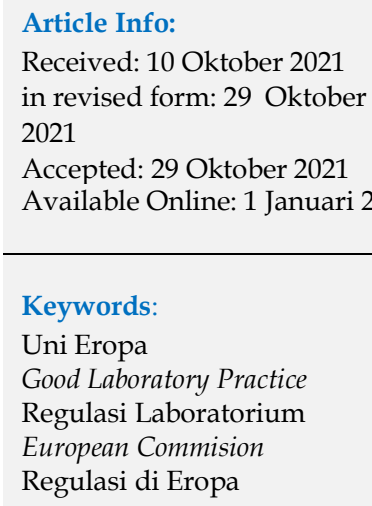

Corresponding Author: Viviane Annisa

Pasca Sarjana Farmasi

Fakultas Farmasi

Universitas Gadjah Mada

Yogyakarta

Indonesia

E-mail:

vivianeannisa@ugm.ac.co.id

\begin{abstract}
GLP (Good Laboratory Practice) regulations regulate how to work in laboratories, personnel training, standard operating procedures, software for data recording, documentation, etc. The main goal of GLP is to improve the quality of data testing so that each country can produce continuous and continuous testing of data, avoid repeated testing, and save time. The members of the OECD (Organization for Economic Cooperation and Development) are 29 countries around the world, including Asia-Pacific, America, and Europe. Adherence to the GLP can remove trade barriers between member countries. The GLP principles applied in the European Union are similar to those of the OECD, namely to improve the quality of testing valid data. This study aims to review about Good Laboratory Practice in European Union. The European Union adopted the GLP regulations in 1987. The amendments related to the GLP were carried out following the OECD in 1999. The EU regulatory regulations on GLP 'Directive 2004/9/EC' was later added 'Directive 88/320/EEC' explaining what was given to member states of the Union Europe to establish GLP inspections in each region and Mutual Acceptance of Data (MAD) requirements. Nonclinical testing of medicinal products in accordance with the provisions of the GLP refers to the OECD and European Union legislation consisting of 'Directive 2004/10/EC' and 'Directive 2004/9/EC'.
\end{abstract}




\begin{abstract}
ABSTRAK
Regulasi GLP (Good Laboratory Practice) mengatur tentang cara bekerja pada laboratorium, pelatihan personel, standar operasional prosedur, software untuk pencatatan data, dokumentasi, dsb. Tujuan utama dari prinsip GLP adalah mengembangkan kualitas dari data pengujian sehingga tiap negara tersebut dapat menghasilkan data pengujian yang andal, menghindari pengujian berulang, serta menghemat waktu. Anggota OECD (Organization for Economic Co-operation and Development) sebanyak 29 negara di seluruh dunia, mencakup AsiaPasifik, Amerika, serta Eropa. Patuh terhadap GLP dapat meniadakan barier perdagangan antar negara anggota. Prinsip GLP yang diaplikasikan di Uni Eropa sejalan dengan OECD, yakni untuk meningkatkan kualitas data pengujian yang valid. Anggota negara Uni Eropa adalah sebanyak 27 negara. Uni Eropa mengadopsi peraturan GLP pada tahun 1987. Amandemen terkait GLP dilakukan mengikuti OECD pada tahun 1999. Peraturan perundangan Uni Eropa tentang GLP 'Directive 2004/9/EC' kemudian menggantikan 'Directive 88/320/EEC' menjelaskan tentang tanggungjawab yang diberikan kepada anggota negara Uni Eropa untuk menetapkan otoritas inspeksi GLP pada masing-masing wilayah dan persyaratan Mutual Acceptance of Data (MAD). Pengujian non-klinik pada produk obat sesuai dengan ketentuan GLP mengacu pada OECD serta peraturan perundangan Uni Eropa yang terdiri dari ‘ Directive 2004/10/EC' dan 'Directive 2004/9/EC'. Meskipun Inggris sudah keluar dari Uni Eropa, namun Mutual Acceptance of Data (MAD) tetap berlaku pada Inggris terhadap negara Eropa lainnya yang sama-sama anggota dari OECD. Otoritas terhadap inspeksi serta audit studi diserahkan pada negara masing-masing anggota.
\end{abstract}

Kata Kunci: Uni Eropa; Good Laboratory Practice: Regulasi Laboratorium; European Commision; Regulasi Eropa

\title{
1. Pendahuluan
}

Good Laboratory Practice (GLP) merupakan pedoman yang mengatur persyaratan dan kriteria sistem manajemen kualitas untuk organisasi dan laboratorium kesehatan nonklinis untuk memastikan kualitas dan keamanan dari bahan kimia serta produk obat dengan menyediakan data pengujian yang reliable, traceable, dan reprodusible. Selain itu juga untuk menjaga kesehatan manusia dan hewan. Fasilitas pengujian produk farmasi harus patuh terhadap regulasi GLP. Regulasi GLP mengatur tentang cara bekerja pada laboratorium, pelatihan personel, standar operasional prosedur, software untuk pencatatan data, dokumentasi, dsb. Patuh terhadap GLP dapat membantu peneliti untuk memperoleh data pengujian sesuai yang dengan protokol yang dimiliki. Tujuan utama dari prinsip GLP adalah mengembangkan kualitas dari data pengujian sehingga tiap negara tersebut dapat menghasilkan data pengujian yang andal, menghindari pengujian berulang, serta menghemat waktu. Aplikasi GLP pada laboratorium penelitian akan meningkatkan kualitas dari kesehatan manusia dan lingkungan [1].

New Zealand merupakan negara pertama yang memperkenalkan GLP pada tahun 1972 sebagai Testing Laboratory Registration Act untuk mendorong perilaku penelitian yang sesuai di laboratorium. Denmark juga mengimplementasikan GLP pada tahun yang sama. Pada tahun 1976, FDA membuat regulasi GLP tentang laboratorium non-klinik. Kemudian pada tahun 1981, Organization for Economic Co-operation and Development (OECD) mengambil keputusan untuk membuat Mutual Acceptance of Data (MAD) [2]. OECD merupakan organisasi internasional yang bekerja bersama pemerintah, warga negara, pembuat keputusan untuk mengkoordinasi, mengharmonisasi, serta 
membangun normal internasional dalam berbagai tantangan sosial, ekonomi, dan lingkungan. OECD mendiskusikan isu yang menjadi perhatian bersama dan bekerja sama untuk merespon permasalahan interansional [1].

Anggota OECD sebanyak 29 negara di seluruh dunia, mencakup Asia-Pasifik, Amerika, serta Eropa. Patuh terhadap GLP dapat meniadakan barier perdagangan antar negara anggota. GLP di Uni Eropa secara hukum diperkenalkan pada tahun 1987 mengacu pada peraturan perundangan 'Directive $87 / 18 / \mathrm{EEC}^{\prime}$ kemudian diamandemen pada tahun 1999 menjadi 'Directive 1999/11/EC' lalu diamandemen lagi tahun 2004 menjadi 'Directive 2004/10/EC' [1]. Pada review artikel ini akan dilakukan tinjauan tentang GLP yang ada pada negara uni eropa.

\section{Hasil dan Pembahasan}

\subsection{GLP di Negaara Uni Eropa}

Anggota negara Uni Eropa adalah sebanyak 27 negara (Gambar 1), yaitu Austria, Belgia, Bulgaria, Kroasia, Siprus, Republik Ceko, Denmark, Estonia, Finlandia, Perancis, Jerman, Yunani, Hungaria, Irlandia, Italia, Latvia, Lituania, Luksembourg, Malta, Belanda, Polandia, Portugal, Romania, Slovakia, Slovenia, Spayol, dan Swedia.

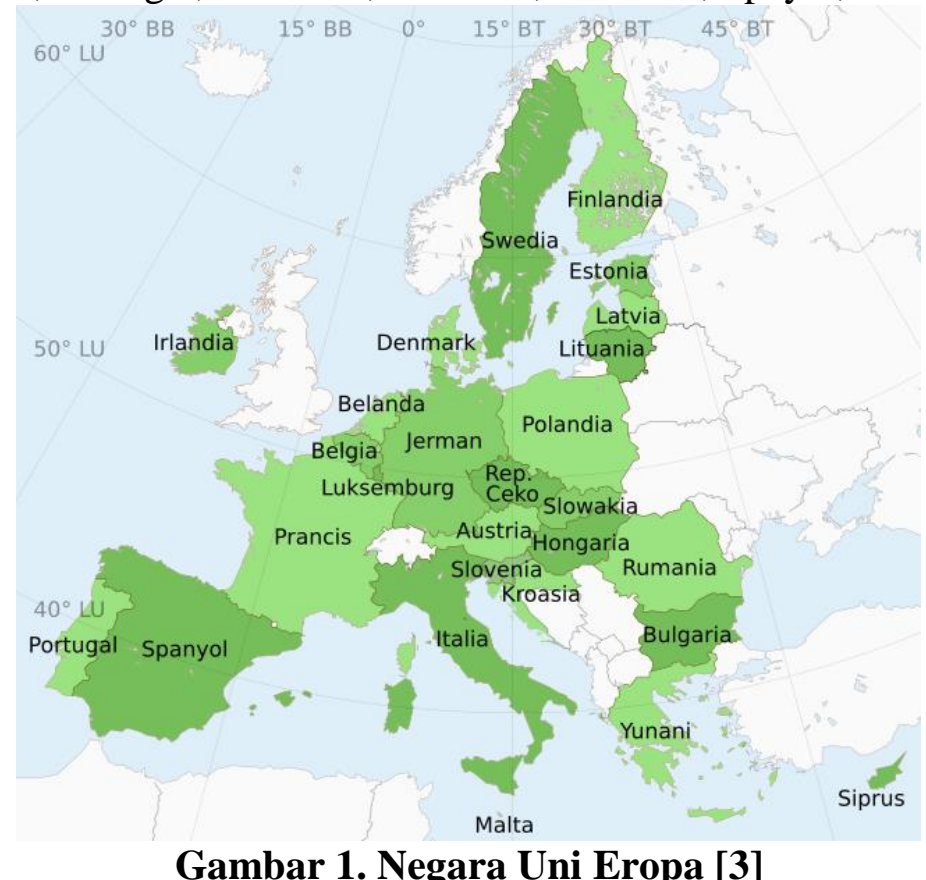

Prinsip GLP yang diaplikasikan di Uni Eropa sejalan dengan OECD, yakni untuk meningkatkan kualitas data pengujian yang valid. Uni Eropa mengadopsi peraturan GLP pada tahun 1987. Amandemen terkait GLP dilakukan mengikuti OECD pada tahun 1999. Peraturan perundangan Uni Eropa tentang GLP 'Directive 2004/9/EC' kemudian menggantikan 'Directive 88/320/EEC' menjelaskan tentang tanggungjawab yang diberikan kepada anggota negara Uni Eropa untuk menetapkan otoritas inspeksi GLP pada masing-masing wilayah dan persyaratan Mutual Acceptance of Data (MAD). MAD diadopsi oleh dewan OECD pada tahun 1981 yang memungkinkan untuk anggota OECD menerima hasil pengujian dari negara anggota lainnya yang mengikuti pedoman pengujian OECD dan prinsip GLP. Peraturan perundangan lainnya adalah 'Directive 
2004/10/EC' yang menggantikan 'Directive 87/18/EEC' menjelaskan tentang pedoman pemeriksaan terkait keselamatan dalam menangani produk kimia di laboratorium yang harus mematuhi prinsip OECD.

Informasi yang lebih lengkap tentang GLP khususnya produk obat di Uni Eropa dapat diperoleh sesuai dengan pedoman di OECD dan European Commission [4]. 'Directive 2004/10/EC' merupakan peraturan perundangan yang mengatur tentang harmonisasi hukum, regulasi, dan ketentuan adminsitratif tentang aplikasi dari prinsip GLP dan verifikasi hasil implementasinya untuk pengujian pada subtansi kimia. Berikut poin yang tetuang dalam 'Directive 2004/10/EC':

- Seluruh negara anggota Uni Eropa harus mengambil langkah yang diperlukan untuk memastikan bahwa laboratoriumnya melakukan pengujian produk kimia sesuai dengan 'Directive 67/548/EEC' yang mematuhi prinsip GLP.

- Pada saat melakukan submit hasil, laboratorium harus menyatakan bahwa hasil pengujian telah dilakukan sesuai dengan prinsip GLP.

- Seluruh negara anggota mengadopsi langkah yang diperlukan untuk memverifikasi kepatuhan terhadap prinsip GLP. Langkah tersebut mencakup, khususnya inspeksi dan audit studi berdasarkan rekomendasi dari OECD.

- Setiap negara anggota menginformasikan kepada Komisiener terkait nama dari otoritas yang bertanggungjawab untuk melakukan verifikasi kepatuhan terhadap prinsip GLP. Komisioner lalu menginformasikan ke anggota lainnya.

- Apabila peraturan perundangan ini sudah berlaku, maka negara anggota tidak boleh melarang, membatasi atau menghambat penempatan pasar dari produk kimia jika prinsip yang diterapkan oleh laboratorium telah sesuai dengan peraturan perundangan ini.

- Sebaiknya negara anggota menetapkan dasar bukti atau petunjuk detail terhadap aplikasi dari prinsip GLP dan verifikasi untuk pengujian subtansi kimia. Meskipun subtansi kimia telah periksa sesuai dengan peraturan perundangan ini. Sebab subtansi kimia dapat berbahaya untuk manusia dan lingkungan. Negara anggota dapat melarang untuk sementara atau membuat persyaratan khusus untuk memasarkan subtansi kimia pada wilayah tersebut. Hal ini perlu diinformasikan langsung pada Komisioner dan anggota negara lainnya dan memberikan alasan terkait keputusannya.

- Komisioner seharusnya dalam waktu 6 minggu melakukan konsultasi ke negara anggota dan memberikan opini serta mengambil langkah yang sesuai tanpa ditunda.

- Jika Komisioner menganggap bahwa adaptasi teknis pada peraturan perundangan ini diperlukan, maka adaptasi tersebut harus diadopsi oleh Komisioner atau Dewan sesuai dengan prosedur. Dalam hal ini, negara anggota yang mengadopsi langkahlangkah upaya perlindungan dapat digunakan sampai berlakunya adaptasi tersebut [5].

\subsection{Transisi Brexit Terhadap GLP di Uni Eropa}

Inggris telah menyerahkan pemberitahuan untuk menarik diri dari Uni Eropa atau dikenal dengan Brexit (Britania Exit) pada tanggal 29 Maret 2017. Hal ini sesuai dengan Pasal 50 dari Perjanjian Uni Eropa. Dewan Eropa telah menyetujui permintaan Inggris keluar dari Uni Eropa pada tanggal 11 April 2019 untuk memperpanjang periode hingga tanggal 31 Oktober 2019. Dengan kata lain, Inggris telah resmi keluar dari Uni Eropa 
atau menjadi 'negara ketiga' mulai tanggal 1 November 2019. Sejalan dengan itu, maka peraturan pada sektor GLP tidak berlaku lagi di Inggris.

Inggris merupakan anggota OECD, sama dengan negara Uni Eropa lainnya, seperti Belgia, Republik Ceko, Denmark, Jerman, Estonia, Irlandia, Yunani, Spayol, Perancis, Italia, Hungaria, Belanda, Austria, Polandia, Portugal, Slovenia, Slovakia, Finlandia, dan Swedia. Maka dari itu, Mutual Acceptance of Data (MAD) tetap berlaku antara Inggris dan negara Eropa lainnya yang sama-sama anggota dari OECD. Namun, hal yang tidak berlaku lagi setelah Inggris memutuskan untuk keluar adalah keikutsertaan dalam program monitoring kepatuhan GLP OECD. Inggri dapat memiliki untuk tidak ikut berpartisipasi dalam program monitoring kepatuhan GLP OECD seperti negara Bulgaria, Kroasia, Siprus, Malta, dan Romania. Namun, apabila memustuskan untuk berpartisipasi, maka negara Uni Eropa yang tergabung dalam OECD dapat menerima data dari Inggris, tetapi Inggris tidak dapat menerima data dari anggota Uni Eropa lainnya.

Semua prosedur hukum seperti peraturan perundangan 'Directive 2004/9/EC' tentang inspeksi dan verifikasi GLP sudah tidak berlaku antara negara Uni Eropa dan Inggris [6].

\subsection{Inspeksi dan Verifikasi GLP}

Inspeksi adalah proses penilaian di tempat yang mengacu pada prinsip GLP OECD yang diadopsi oleh komunitas Uni Eropa. Inspeksi dan verifikasi GLP khususnya diatur pada peraturan perundangan 'Directive 2004/9/EC'. Berikut poin yang tetuang dalam 'Directive 2004/9/EC':

- Peraturan ini berlaku untuk inspeksi dan verifikasi proses organisasi dan kondisi dibawah laboratorium pada pengujian non-klinik untuk seluruh zat kimia, seperti bahan kimia industri, obat, kosmetik, zat aditif makanan, dan pestisida untuk menilai efek produk terahdap manusia, hewan, dan lingkungan.

- Negara anggota harus memverifikasi kepatuhan setiap laboratorium pengujian di wilayah mereka terhadap GLP.

- Negara anggota harus menunjuk otoritas di wilayah mereka yang bertanggungjawab untuk inspeksi laboratorium serta untuk audit kepatuhan terhadap GLP.

- Setiap tahun, negara anggota harus menyusun laporan terkait implementasi GLP di wilayah mereka. Laporan ini harus dilaporkan kepada Komisioner. Nama laboratorium yang diinspeksi, status kepatuhan GLP, serta tanggal inspeksi tidak dianggap rahasia.

- Apabila laboratorium di suatu negara anggota yang diklaim patuh terhadap GLP, tetapi tidak sesuai dengan fakta di lapangan, maka negara anggota tersebut harus segera melapor pada Komisioner. Lalu komisioner akan menginformasikan ke anggota lainnya.

- Sedangkan apabila negara anggota lain menemukan ketidaksesuaian GLP dengan fakta di lapangan pada suatu negara anggota, maka negara anggota lain dapat meminta informasi terlebih dahulu kepada negara anggota tersebut dan dapat meminta untuk inspeksi atau audit studi ulang [7]. 
Pada standar operasional prosedur European Medicine Agency yang mengatur tentang Co-Ordination of GLP Inspections khususnya untuk permintaan audit studi, terdapat beberapa tahapan inspeksi yang harus dilakukan, yakni: menilai kepatuhan GLP, mempersiapkan permintaan inspeksi, mempersiapkan surat pemberitahuan, melakukan inspeksi, validasi laporan inspeksi, serta mempersiapkan surat hasil audit [8].

\subsection{Implementasi GLP pada Negara Uni Eropa}

Implementasi dari prinsip GLP dan monitoring kepatuhan adalah untuk mengadopsi tindakan legal yang diperlukan, membuat program kepatuhan nasional, inspeksi dan audit studi, serta laporan laporan tahunan [2]. Dibawah ini akan dijabarkan terkait otoritas monitoring GLP serta inspeksi atau audit studi [9]. Namun, negara yang belum memiliki otoritas inspeksi GLP seperti Bulgaria, Kroasia, dan Romania tidak dijabarkan disini.

\subsubsection{Austria}

Otoritas monitoring GLP untuk seluruh zat kimia kecuali produk obat dipegang oleh Badan Kementerian Pertanian dan Kehutanan, Lingkungan dan Manajemen Air sedangkan otoritas pada produk obat dipegang oleh The Austrian Federal Office for Safety in Health Care. Inspeksi dilakukan oleh The Austrian Agency for Health and Food Safety setiap 2-3 tahun.

\subsubsection{Belgia}

Otoritas monitoring GLP dipegang oleh The Federal Departement of Public Health, The Food Chain Safety and Environment. Untuk seluruh produk kimia dipegang oleh Scientific Institute of Public Health. Fasilitas pengujian untuk produk kimia, mencakup industri kimia, produk obat, obat hewan, fitofarmasetika, zat aditif makanan serta produk kosmetik. Inspeksi dilakukan setiap 2-3 tahun.

\subsubsection{Siprus}

Otoritas monitoring GLP dipegang oleh Kementerian Perdagangan, Industri, dan Turisme dan sebagian oleh Cyprus Organizatioin for Pormoting Quality. Belum ada fasilitas pengujian GLP di Siprus.

\subsubsection{Republik Ceko}

Otoritas monitoring GLP dipegang oleh Kementerian Lingkungan untuk semua sektor kecuali produk farmasi. Untuk produk farmasi dipegang oleh The State Institute for Drug Control dibawah Kementerian Kesehatan. Inspeksi dilakukan setiap 2-3 tahun.

\subsubsection{Denmark}

Otoritas monitoring GLP dipegang oleh Kementerian Kesehatan dan Kementerian Perdagangan dan Industri. Danish Medicines Agency bertanggungjawab terhadap produk obat, sedangkan Danish Acccreditation and Metrology Fund (DANAK) bertanggungjawab pada sektor perlindungan produk, biosida, dan zat aditif makanan. DANAK melakukan inspeksi setiap 2-3 tahun.

\subsubsection{Estonia}

Otoritas monitoring GLP dipegang oleh The Estonian Accreditation Centre (EAK) dibawah Kementerian Sosial. Swedish Board of Accreditation and Conformity Assessment melakukan inspeksi dengan EAK.

\subsubsection{Finlandia}


Otoritas monitoring GLP dipegang oleh The National Produc Agency for Welfare and Health yang juga bertanggungjawab untuk memonitoring fasilitas pengujian keamanan pada bahan kimia. Untuk produk obat, inspeksi dilakukan oeh The National Agency for Medicine.

\subsubsection{Perancis}

Otoritas monitoring GLP dipegang oleh The Groupe Interministeriel des Peroduits Chimiques untuk sektor bahan kimia. Untuk produk obat dan kosmetik dipegang oleh Kementerian Tenaga Kerja dan Sosial. Fasilitas pengujian mencakup bahan kimia, produk obat, kosmetik zat aditif makanan, serta pestisida. Inspeksi dilakukan antara 15 bulan untuk bahan kimia dan setiap 2 tahun untuk produk obat dan kosmetik.

\subsubsection{Jerman}

Otoritas monitoring GLP dipegang oleh Kementerian Lingkungan, Konservasi Alam dan Keamanan Nuklir. Fasilitas pengujian mencakup bahan kimia, produk obat, kosmetik zat aditif makanan, pestisida, kosmetik, dan bahan peledak. Inspeksi rutin dilaksanakan setiap 4 tahun setelah inspeksi terakhir. Inspeksi tambahan dan audit studi bisa dengan mengajukan permintaan

3.4.10 Yunani

Otoritas monitoring GLP dipegang oleh General Chemical State Laboratory dibawah Kementerian Keuangan. Fasilitas pengujian di Yunani sebagian besar untuk produk pelindung tanamana. Inspeksi rutin dilaksanakan setiap tahun kedua.

\subsubsection{Hungaria}

Otoritas monitoring GLP dipegang oleh The National Institute of Pharmacy dibawah Kementerian Kesehatan untuk produk obat manusia saja. Inspeksi rutin dilaksanakan setiap 2 tahun.

\subsubsection{Irlandia}

Otoritas monitoring GLP dipegang oleh The Irish National Accreditation Board dibawah The Irish Departement of Enterprise, Trade, and Employment. Inspeksi rutin dilaksanakan setiap tahun kedua.

\subsubsection{Italia}

Otoritas monitoring GLP dipegang oleh Dipartimento Prevenzione dibawah Kementerian Kesehatan. Fasilitas pengujian melakukan monitoring pada produk obat, pestisida, zat aditif makanan, kosmetik, dan bahan kimia industri.

\subsubsection{Latvia}

Otoritas implementasi GLP dipegang oleh Kementerian Perlindungan Lingkungan dan Perkembangan Regional sedangkan monitoring GLP dipegang oleh Latvian National Accreditation Bureau. Inspeksi GLP telah dimulai pada tahun 2007, tetapi belum ada yang sesuai dengan OECD atau evaluasi Uni Eropa. Inspeksi rutin dilaksanakan setiap 2 tahun.

\subsubsection{Lituania}

Otoritas monitoring GLP dipegang oleh The Lithuanian National Accreditation Bureau dibawah Kementerian Lingkungan. Inspeksi rutin dilaksanakan setiap tahun kedua, tetapi sejauh ini belum ada laboratorium yang mengikuti program.

\subsubsection{Luksemburg}

Otoritas monitoring GLP dipegang oleh The Institut Luxembourgeois De La Normalisation, De L'accréditation, De La Sécurité Et Qualité Des Produits Et 
Services (ILNAS). Inspeksi dilakukan oleh ILNAS bekerjasama dengan otoritas GLP Belgia.

\subsubsection{Malta}

Otoritas monitoring GLP dipegang oleh The National Accreditation Body Malta Standards Authority (NAB-MSA). Inspeksi dilakukan oleh MSA yang bekerja sama dengan otoritas GLP Irlandia. Belum ada fasilitas pengujian di Malta.

3.4.18 Belanda

Otoritas monitoring GLP dipegang oleh The Health Care Inspectorate dibawah Kementerian Kesehatan, Kesejahteraan, dan Olahraga. Fasilitas pengujian melakukan monitoring pada bahan kimia industri, produk obat, dan pestisida.

3.4.19 Polandia

Otoritas monitoring GLP dipegang oleh The Bureau for Chemical Sustances and Preparations dibawah Kementerian Kesehatan. Inspeksi mencakup sektor produk kimia secara luas.

3.4.20 Portugal

Otoritas monitoring GLP dipegang oleh Instituto da Farmacia e do Medicamento dibawah Kementerian Kesehatan untuk produk obat dan kosmetik. Untuk produk kimia lainnya dipegang oleh Instituto Portugues da Qualidade dibawah Kementerian Ekonomi. Inspeksi rutin dilaksanakan setiap 2 tahun.

\subsubsection{Slovakia}

Otoritas monitoring GLP dipegang oleh Slovak National Accrediation Service dibawah Kementerian Ekonomi. Inspeksi rutin dilaksanakan setiap 16 bulan. Monitoring GLP pada sektor produk obat, bahan kimia industri, produk pelindung tanaman, kosmetik, biosida, dan zat aditif makanan.

\subsubsection{Slovenia}

Otoritas monitoring GLP dipegang oleh The National Chemicals Bureau dibawah Kementerian Kesehatan. Fasilitas pengujian mencakup sektor produk obat, zat aditif makanan, biosida, dan bahan kimia industri.

\subsubsection{Spanyol}

Otoritas monitoring GLP dipegang oleh Directorate General of Pharmacy and Hygiene dibawah Kementerian Kesehatan dan Konsumsi untuk produk obat. Untuk produk lainnya dipegang oleh The Entidad Nacional de Acreditacion. Saat ini, monitoring GLP hanya untuk produk obat dan produk pelindung tanaman.

\subsubsection{Swedia}

Otoritas monitoring GLP dipegang oleh Medical Product Agency (MPA) dibawah Kementerian Sosial untuk produk farmasi, kosmetik, dan produk pembersih hygiene. Untuk bahan kimia lainnya dipegang oleh Swedish Board of Accreditation and Conformity Assessment (SWEDAC) dibawah Kementerian Luar Negeri. Inspeksi rutin SWEDAC dilakukan setiap tahun sedangkan MPA dilakukan setiap 2 tahun.

\section{Kesimpulan}

Pengujian non-klinik pada produk obat sesuai dengan ketentuan GLP mengacu pada OECD serta peraturan perundangan Uni Eropa yang terdiri dari 'Directive 2004/10/EC' dan 'Directive 2004/9/EC'. Meskipun Inggris sudah keluar dari Uni Eropa, namun Mutual Acceptance of Data (MAD) tetap berlaku pada Inggris terhadap negara Eropa lainnya yang sama-sama anggota dari OECD. Otoritas terhadap inspeksi serta audit studi diserahkan pada negara masing-masing anggota. 


\section{Ucapan Terima Kasih}

Penulis menyampaikan ucapan terima kasih kepada Bu Rina Kuswahyuning, M.Si., Ph.D., Apt. atas ilmu yang telah diberikan tentang mata kuliah Penjaminan Mutu sehingga penulis termotivasi untuk menulis dan mempublikasikan artikel ini.

\section{Referensi}

[1] Ravi GS, Dubey A, Shetty K, et al. Good laboratory practices: Need of the hour. Pharma Times 2019; 51: 9-11.

[2] Schmahl M. GLP in the European Union - Overview and Role of the Commission and the Member States. Brusel, 2006.

[3] Wikipedia. European Union, https://id.wikipedia.org/wiki/Uni_Eropa (2020, accessed 30 April 2020).

[4] European Medicines Agency. Good Laboratory Practice Compliance, https://www.ema.europa.eu/en/human-regulatory/researchdevelopment/compliance/good-laboratory-practice-compliance (2015, accessed 30 April 2020).

[5] European Parliament and of The Council. DIRECTIVE 2004/10/EC. Strasbourg: Official Journal of The European Union, 2004.

[6] European Commision. Withdrawal of The United Kingdom and Rules in The Field of Good Laboratory Practice (GLP). Brusel, 2019.

[7] European Parliament and of The Council. DIRECTIVE 2004/9/EC. Strasbourg: Official Journal of The European Union, 2004.

[8] European Medicines Agency. Standard Operating Procedure Co-Ordination of GLP Inspections. Belanda, 2012.

[9] European Commision. Implementation of The GLP Directives in The European States. Brusel, 2015. 